This is the final peer-reviewed accepted manuscript of:

Paola Taddei, Silvia Tozzi, Giampaolo Zuccheri, Simona Martinotti, Elia Ranzato, Valeria Chiono, Irene Carmagnola, Masuhiro Tsukada,

"Intermolecular interactions between B. mori silk fibroin and poly(L-lactic acid) in electrospun composite nanofibrous scaffolds"

Materials Science and Engineering: C, Volume 70, Part 1, 2017, Pages 777-787, ISSN 0928-4931.

The final published version is available online at: https://doi.org/10.1016/j.msec.2016.09.055

Rights / License:

The terms and conditions for the reuse of this version of the manuscript are specified in the publishing policy. For all terms of use and more information see the publisher's website.

This item was downloaded from IRIS Università di Bologna (https://cris.unibo.it/)

When citing, please refer to the published version. 


\title{
Intermolecular interactions between $B$. mori silk fibroin and poly(L-lactic acid) in electrospun composite nanofibrous scaffolds
}

\author{
Paola Taddei $^{\mathrm{a}, *}$, Silvia Tozzi ${ }^{\mathrm{a}}$, Giampaolo Zuccheri ${ }^{\mathrm{b}, \mathrm{c}}$, Simona Martinotti ${ }^{\mathrm{d}}$, Elia Ranzato ${ }^{\mathrm{d}}$, Valeria Chiono ${ }^{\mathrm{e}}$, \\ Irene Carmagnola ${ }^{\mathrm{e}}$, Masuhiro Tsukada ${ }^{\mathrm{f}}$ \\ ${ }^{a}$ Dipartimento di Scienze Biomediche e Neuromotorie, Università di Bologna, Via Belmeloro 8/2, 40126 Bologna, Italy \\ ${ }^{\mathrm{b}}$ Dipartimento di Farmacia e Biotecnologie e Centro Interdipartimentale di Ricerca Industriale Scienze della Vita e Tecnologie per la Salute, Università di Bologna, Via Irnerio \\ 48, 40126 Bologna, Italy \\ ${ }^{c}$ Centro S3, Istituto Nanoscienze, Consiglio Nazionale delle Ricerche; Consorzio Interuniversitario Nazionale per la Scienza e Tecnologia dei Materiali, Italy \\ d Dipartimento di Scienze e Innovazione Tecnologica, DiSIT, Università del Piemonte Orientale, viale Teresa Michel 11, 15121 Alessandria, Italy \\ e Dipartimento di Ingegneria Meccanica e Aerospaziale, Politecnico di Torino, Corso Duca degli Abruzzi 24, 10129 Torino, Italy \\ ${ }^{\mathrm{f}}$ Division of Applied Biology, Faculty of Textile Science and Technology, Shinshu University, 3-15-1, Tokida, Ueda, Nagano 386-8567, Japan
}

\section{A R T I C L E I N F O}

\section{Article history:}

Received 6 July 2016

Received in revised form 1 September 2016

Accepted 26 September 2016

Available online $\mathrm{xxx}$

\section{Keywords:}

Electrospinning

Vibrational spectroscopy

AFM

SEM

Keratinocytes cell cultures

\section{A B S T R A C T}

In this study, composite nanofibrous scaffolds were obtained by electrospinning a trifluoroacetic acid solution containing B. mori silk fibroin (SF) and poly(L-lactic acid) (PLLA) in a 1:1 weight ratio. SF, PLLA and SF/PLLA nanofibres were prepared with average diameter sizes of $360 \pm 90 \mathrm{~nm}, 470 \pm 240 \mathrm{~nm}$ and $580 \pm 220 \mathrm{~nm}$, respectively, as assessed by SEM analysis.

Vibrational and thermal analyses showed that upon blending in the SF/PLLA nanofibres, the crystallisation of PLLA was hindered by the presence of SF, which crystallized preferentially and underwent conformational changes that did not significantly change its prevailing $\beta$-sheet structure. The two components were thermodynamically compatible and the intermolecular interactions between them were revealed for the first time.

Human keratinocytes were cultured on nanofibres and their viability and proliferation were determined. Preliminary in vitro tests showed that the incorporation of SF into the PLLA component enhanced cell adhesion and proliferation with respect to the unfunctionalised material. SF has been successfully used to modify the biomaterial properties and confirmed to be an efficient bioactive protein to mediate cell-biomaterial interaction.

C 2016 Published by Elsevier Ltd.

\section{Introduction}

Silk fibroin (SF) has been widely used for biomedical applications (wound healing and tissue engineering) due to its outstanding mechanical properties, good oxygen and water vapour permeability, hemocompatibility, lower inflammatory response than collagen, controlled proteolytic biodegradation, morphologic flexibility. Furthermore, its ability to support stem cell adhesion, proliferation, and differentiation in vitro and promote tissue regeneration are well known [1-4]. In this context, electrospinning has proved a popular and effective process for producing nanofibrous scaffolds usable for drug delivery, wound dressing and tissue engineering. The produced fibres have high specific surface area and high porosity, therefore, the micro/nanofibres can simulate the extracellular matrix and enhance cell migration and proliferation.

An appealing strategy towards obtaining biomimetic nanofibres consists in processing naturally derived polymers [5-7]. A single material hardly fulfils all the requirements of a specific biological function. Consequently, SF-based composites have been designed as a

\footnotetext{
* Corresponding author at: Dipartimento di Scienze Biomediche e Neuromotorie, Via Belmeloro 8/2, 40126 Bologna, Italy.

Email address: paola.taddei@unibo.it (P. Taddei)
}

strategy to achieve properly modified and tailored materials [8-15]. On the way to develop bioresorbable composite scaffolds, several studies have been performed on the influence of SF on the biodegradation properties of synthetic polymeric materials [11-15]. Aliphatic polyesters, such as poly(L-lactic acid) (PLLA), have been the most widely bioresorbable polymers used to date; PLLA is a biocompatible polymer used since a long time in many biomedical applications (resorbable sutures, wound-healing materials, artificial skin grafts, orthopaedic fixation devices, controlled drug delivery systems) for its outstanding properties such as strength and controlled degradation $[16,17]$. However, PLLA has a low hydrophilicity and does not contain cell recognition sites.

The use of polyblend nanofibres obtained by electrospinning mixtures of synthetic and natural polymers has gained increasing attention in tissue engineering, due to the possibility of retaining the mechanical strength and durability of a synthetic component and the biological functionality of a natural polymer. B. mori SF has been recently used to obtain electrospun blended nanofibres in combination with poly(L-lactic acid-co-e-caprolactone) (PLLA-CL) [18], PLLA and gelatine [8], poly(ethylene oxide) [19], poly(L-lactic-co-glycolic acid) [20], PEG-plasticised PLLA [21]. Spider, A. pernyi and Eri SF/ PLLA composite nanofibres have been prepared and characterised [22-25]. 
Most of the above mentioned studies have focused their attention on blended devices where SF was the prevailing component $[8,11,22,23,25]$, while others have explored the effect of the SF/polyester weight ratio on the chemical, physical and biological properties of the scaffold $[13-15,18,24]$. In the present investigation, composite nanofibrous scaffolds were obtained by electrospinning a trifluoroacetic acid solution containing regenerated $B$. mori SF and PLLA in a 1:1 weight ratio. In agreement with Lv et al. [12], this ratio has been chosen to combine the advantageous properties of both constituents. To induce the transformation into $\beta$-sheet [26], the nanofibres were treated with aqueous methanol. The SF, PLLA and SF/PLLA scaffolds were characterised by Raman and IR vibrational spectroscopy, thermal analysis (Differential Scanning Calorimetry, DSC, and thermogravimetry, TG), atomic force microscopy (AFM) imaging and SEM, to investigate the possible occurrence of intermolecular interactions between the constituents as well as to clarify the effect of electrospinning/methanol treatment and blending on the structure of the scaffolds. Regenerated SF powder and PLLA pellets, used as starting materials, were analysed as control samples.

In vitro biocompatibility of SF, PLLA and SF/PLLA was comparatively evaluated by means of preliminary cell tests using human skin keratinocytes, in order to investigate their potential for biomedical applications.

\section{Materials and methods}

\subsection{Materials}

Silk fibres were obtained from the reeling of B. mori silk cocoon threads. The fibres were cleaned by an acetone/ethanol mixture system to remove the wax, and degummed in an aqueous solution containing sodium carbonate $(3 \mathrm{~g} / \mathrm{L})$, sodium metasilicate $(3 \mathrm{~g} / \mathrm{L})$ and Marseille soap $(2 \mathrm{~g} / \mathrm{L})$ at $98-100{ }^{\circ} \mathrm{C}$ for $90 \mathrm{~min}$ to remove the silk sericin. Finally, the degummed silk fibroin (SF) fibres were washed thoroughly with running water for $2 \mathrm{~h}$. SF solution was prepared by dissolving the SF fibres in $8 \mathrm{M}$ aqueous $\mathrm{LiBr}$ solution at $60^{\circ} \mathrm{C}$ for $30 \mathrm{~min}$, then dialysed against tap water at $5{ }^{\circ} \mathrm{C}$ for 4 days. SF powder was prepared by freeze drying a regenerated $2 \mathrm{wt} \% \mathrm{SF}$ solution.

SF powder and PLLA pellets (Lactron, Kanebo Gousen Ltd., Tokyo) were dissolved in trifluoroacetic acid (TFA, Wako Pure Chemical Industries, Ltd) by stirring at ambient temperature. SF and PLLA nanofibres were produced by electrospinning $10 \mathrm{wt} \% \mathrm{SF}$ and $12 \mathrm{wt} \%$ PLLA TFA solutions, respectively. The composite SF/PLLA nanofibres were obtained by electrospinning a $10 \mathrm{wt} \%$ binary mixture of SF and PLLA (1:1 weight ratio). The electrospinning instruments were from the Kato Tech. Company, Kyoto, Japan. The TFA solution was drawn into a $5 \mathrm{~mL}$ syringe (SS-01T, Terumo Corporation, Tokyo, Japan) using a 21 gauge stainless needle (inner diameter $0.3 \mathrm{~mm}, 38 \mathrm{~mm}$ long, NN-2238N, Terumo Corporation, Tokyo, Japan), which was connected to a high voltage power supply. The flow rate was controlled at $25 \mu \mathrm{L} / \mathrm{min}$ using a syringe pump. A high voltage of around $25 \mathrm{kV}$ was applied. The SF, PLLA and SF/PLLA nanofibres were placed on an aluminium foil placed $15 \mathrm{~cm}$ from the capillary tip. After electrospinning, the SF and SF/PLLA nanofibres were immersed in $50 \% \mathrm{~V} / \mathrm{V}$ methanol solution for $10 \mathrm{~min}$, rinsed with water and allowed to dry at room temperature for $12 \mathrm{~h}$.

\subsection{Raman and IR vibrational spectroscopy}

Raman spectra were recorded on a Bruker MultiRam FT-Raman spectrometer equipped with a cooled Ge-diode detector. The excitation source was a $\mathrm{Nd}^{3+}$-YAG laser $(1064 \mathrm{~nm})$ in the backscattering $\left(180^{\circ}\right)$ configuration. The focused laser beam diameter was about
$100 \mu \mathrm{m}$ and the spectral resolution $4 \mathrm{~cm}^{-1}$. The reported spectra were recorded with a laser power at the sample of about $60 \mathrm{~mW}$.

IR spectra were recorded on a Nicolet 5700 FT-IR spectrometer, equipped with a Smart Orbit diamond ATR accessory and a DTGS detector; the spectral resolution was $4 \mathrm{~cm}^{-1}$. At least five spectra were recorded and averaged on each electrospun sample.

The calculated (i.e. theoretical) Raman and IR spectra of the SF/ PLLA nanofibres were obtained as the average of the two experimental spectra of SF and PLLA nanofibres after baseline correction and normalisation of the Amide I and $\nu \mathrm{C}=\mathrm{O}$ bands, respectively, to the intensity observed in the experimental spectra of the SF/PLLA nanofibres.

\subsection{DSC and TG thermal analyses}

DSC thermograms were obtained by using a Mettler TA-STAR, Model $821^{\mathrm{e}}$ calorimeter, covering $5-330{ }^{\circ} \mathrm{C}$ in a nitrogen atmosphere $\left(80 \mathrm{~mL} / \mathrm{min}\right.$ flow rate). The heating rate was $5{ }^{\circ} \mathrm{C} / \mathrm{min}$. The crystallinity degree $\mathrm{X}_{\mathrm{c}} \%$ of the PLLA component was evaluated according to the equation:

$$
X_{c} \%=\frac{\sum \Delta H_{m}-\sum \Delta H_{\text {exo }}}{\Delta H_{m}^{o}}
$$

where $\Delta \mathrm{H}_{\mathrm{m}}$ is the measured enthalpy of melting, $\Delta \mathrm{H}_{\text {exo }}$ is the measured enthalpy of an exothermal transition, and $\Delta \mathrm{H}_{\mathrm{m}}{ }^{\circ}$ the enthalpy of melting of a theoretically $100 \%$ crystalline polymer $\left(\Delta \mathrm{H}_{\mathrm{m}}{ }^{\circ}=93.6 \mathrm{~J} /\right.$ g).

TG measurements were performed with a Mettler TA-STAR, TGA/SDTA $851^{\mathrm{e}}$ thermobalance, in a nitrogen atmosphere $(80 \mathrm{~mL} /$ min flow rate) with a heating rate of $5{ }^{\circ} \mathrm{C} / \mathrm{min}$, from 30 to $400{ }^{\circ} \mathrm{C}$. TG analysis was used to check the presence of TFA impurities (not detected) as well as to quantify water content.

\subsection{Morphology analysis: scanning electron microscopy}

PLLA, SF and SF/PLLA nanofibres were examined through Scanning Electron Microscopy (SEM) to evaluate fibre morphology. Samples were coated with a thin gold layer using Agar Auto Sputter Coater. Then the samples were analysed through SEM LEO - 1430 (Zeiss) equipment at different magnifications $(500 \times, 1000 \times, 2000 \times$, $3000 \times$ and $5000 \times)$. The average diameter size, the diameter size distribution and the pore size distribution of the electrospun nanofibres were calculated using ImageJ software on $5000 \times$ images.

\subsection{AFM imaging}

For AFM microscope imaging, nanofibre specimens were mounted on flat steel discs by using double-sided adhesive tape. Atomic Force Microscopy imaging was performed in ambient air and room temperature in tapping-mode ${ }^{\mathrm{TM}}$ on a Multimode Nanoscope $\mathrm{V}$ system (Bruker) equipped with a J-type scanner. MikroMash NSC15/AIBS probes (MikroMasch, Estonia) were used. The height and phase signals were acquired simultaneously. Roughness was evaluated as $\mathrm{Rq}$ (i.e. root mean square average of height deviations taken from the mean image data plane); average values over five different measurements were reported.

\subsection{Cellular proliferation and cytotoxicity tests}

$\mathrm{HaCaT}$ cells are immortalised human skin keratinocytes that mimic many properties of normal epidermal keratinocytes, are not in- 
vasive, and can differentiate under appropriate experimental conditions [27]. Cells were maintained at $37^{\circ} \mathrm{C}, 5 \% \mathrm{CO}_{2}$, in DMEM (Sigma-Aldrich) supplemented with $10 \%$ foetal bovine serum (FBS) and $1 \%$ antibiotic mixture.

The lipophilic, nonfluorescent calcein-acetoxymethylester (calcein-AM, Sigma-Aldrich) penetrates cell membranes and is then cleaved by intracellular esterases, yielding the hydrophilic fluorescent dye. Briefly, cells were settled overnight in 96-well plates (8000 cells/ well), incubated with materials for $24 \mathrm{~h}$, washed with PBS, and then incubated for $30 \mathrm{~min}$ at $37^{\circ} \mathrm{C}$ with a solution of $2.5 \mu \mathrm{M}$ calcein-AM in PBS. Plates were read in a fluorescence plate reader (Infinite 200 Pro, Tecan, Wien, Austria), by using 485-nm ex and 535-nm em filters [28].

For crystal violet assay, cells ( 8000 cells/well) were seeded on 96-well, incubated with materials for $24 \mathrm{~h}$, then the medium was removed, cells were gently washed once with $1 \mathrm{xPBS}$, stained with $0.5 \%$ crystal violet for $10 \mathrm{~min}$ and washed three times with water. Crystal violet was eluted from cells with $33 \%$ acetic acid, and absorption of the supernatant from each sample was measured at $540 \mathrm{~nm}$ with Tecan plate reader [27].

\section{Results and discussion}

\subsection{Effect of electrospinning on the PLLA component: vibrational and thermal analyses}

The IR spectra of the PLLA pellet and PLLA nanofibres (Fig. 1, see Table S1, Supplementary material for assignments) show many spectral differences, which revealed a higher crystalline degree for the former.

The spectrum of the pellet showed with higher intensities the bands at $925 \mathrm{~cm}^{-1}$ (undetectable in the spectrum of the nanofibres) and $870 \mathrm{~cm}^{-1}$, assignable to the $\alpha$-crystal form of PLLA (i.e. a distorted $10_{3}$ helix $[29,30]$ ), while the component at $955 \mathrm{~cm}^{-1}$ (due to the amorphous phase $[29,30]$ ) was weaker. Going from the pellet to the nanofibres, the $\mathrm{C}=\mathrm{O}$ stretching at about $1750 \mathrm{~cm}^{-1}$ and the $\mathrm{CH}_{3}$ antisymmetric bending at $1454 \mathrm{~cm}^{-1}$ sharpened, in agreement with Zhang et al. [30], who have reported a splitting of both these modes upon crystallisation, due to a different packing of the groups in the unit cell.

In the $\mathrm{CH}$ bending region, the components observed in the spectrum of the pellet at 1382, 1358 and $1304 \mathrm{~cm}^{-1}$ underwent changes in relative intensities and wavenumber positions upon electrospinning. The band at $1382 \mathrm{~cm}^{-1}$ increased in intensity, according to its assignment to an amorphous phase [30], while the bands at 1358 and $1304 \mathrm{~cm}^{-1}$ decreased in intensity, according to their assignment to the crystalline phase [30]. In the $1300-1000 \mathrm{~cm}^{-1}$ range, where CC, $\mathrm{CO}$ and $\mathrm{COC}$ stretching prevalently fall, the band at $1266 \mathrm{~cm}^{-1}$, assigned to the amorphous phase [30], increased in intensity upon electrospinning. The increase of disorder was confirmed by the trends of the $\mathrm{I}_{1207} / \mathrm{I}_{1180}$ and $\mathrm{I}_{1128} / \mathrm{I}_{1084}$ intensity ratios which decreased from 0.68 to 0.52 and from 0.74 to 0.51 , respectively, as expected on the basis of the assignments of the bands at about 1207 and $1128 \mathrm{~cm}^{-1}$ to crystalline PLLA [30], while those at about 1180 and $1084 \mathrm{~cm}^{-1}$ are due to amorphous PLLA [30].

The trend of the Raman spectra of the PLLA pellet and nanofibres (Fig. 2, see Table S2, Supplementary material for assignments) confirmed the IR findings, showing a higher crystalline character for the pellet.

The $\mathrm{C}=\mathrm{O}$ stretching band displayed different widths, wavenumber positions and structures in the two samples: upon electrospinning, the full-width at half maximum (FWHM) increased due to a more prominent component at $1755 \mathrm{~cm}^{-1}$. In the $\mathrm{CH}$ bending region, the $1275 \mathrm{~cm}^{-1}$ band appeared only in the spectrum of the electrospun sample, according to its more disordered character; moreover, in agreement with Qin and Kean [31], in the spectrum of the less crystalline electrospun sample, the band at $1219 \mathrm{~cm}^{-1}$ was less distinct, while that at $1094 \mathrm{~cm}^{-1}$ appeared more prominent. Going from the pellet to the nanofibres, the $\mathrm{I}_{1129} / \mathrm{I}_{1044}$ intensity ratio decreased from 1.3 to 1.2. According to Yang et al. [32], this trend may be related to changes in the conformational distribution, i.e. to a decreased content of bent conformers (tt'g and tg'g) and an increased content of straight

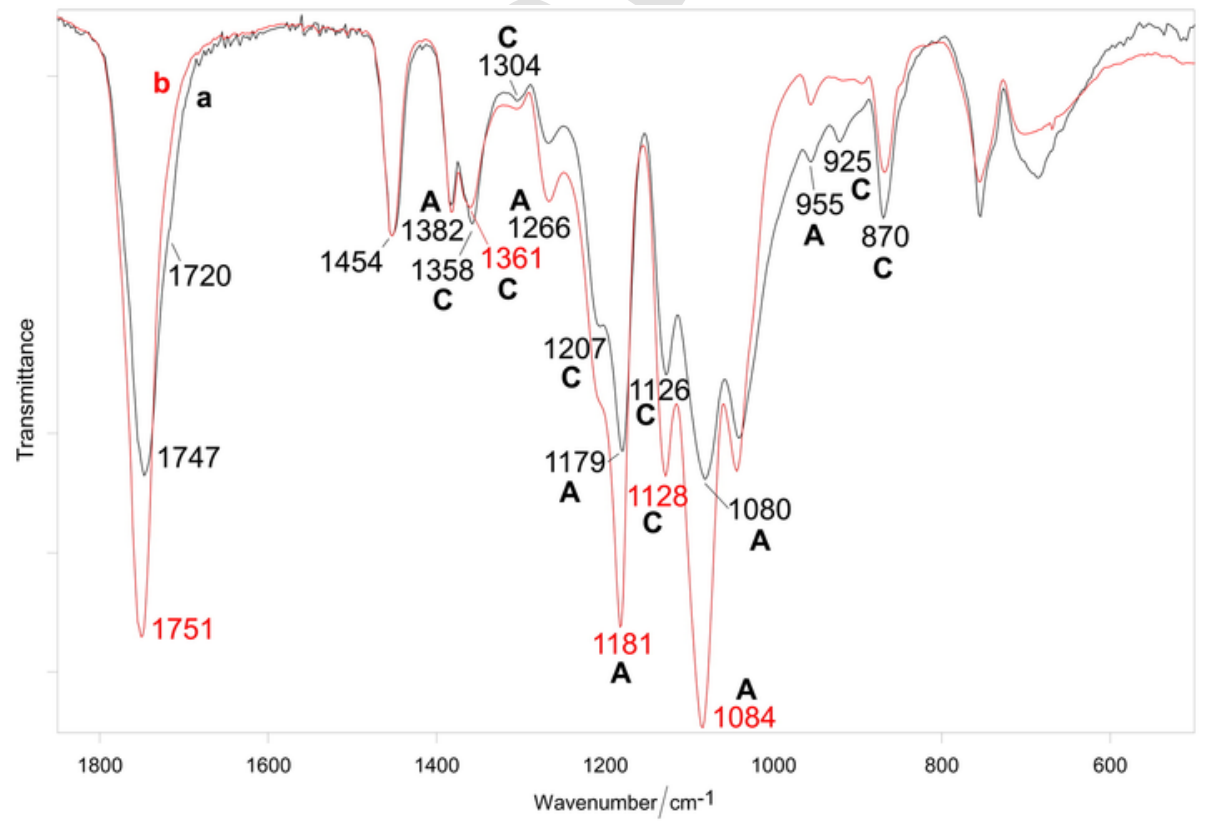

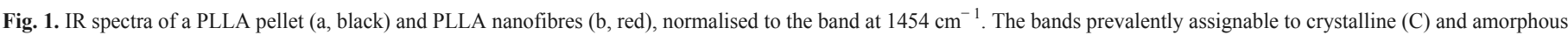
(A) PLLA are indicated. (For interpretation of the references to colour in this figure legend, the reader is referred to the web version of this article.) 

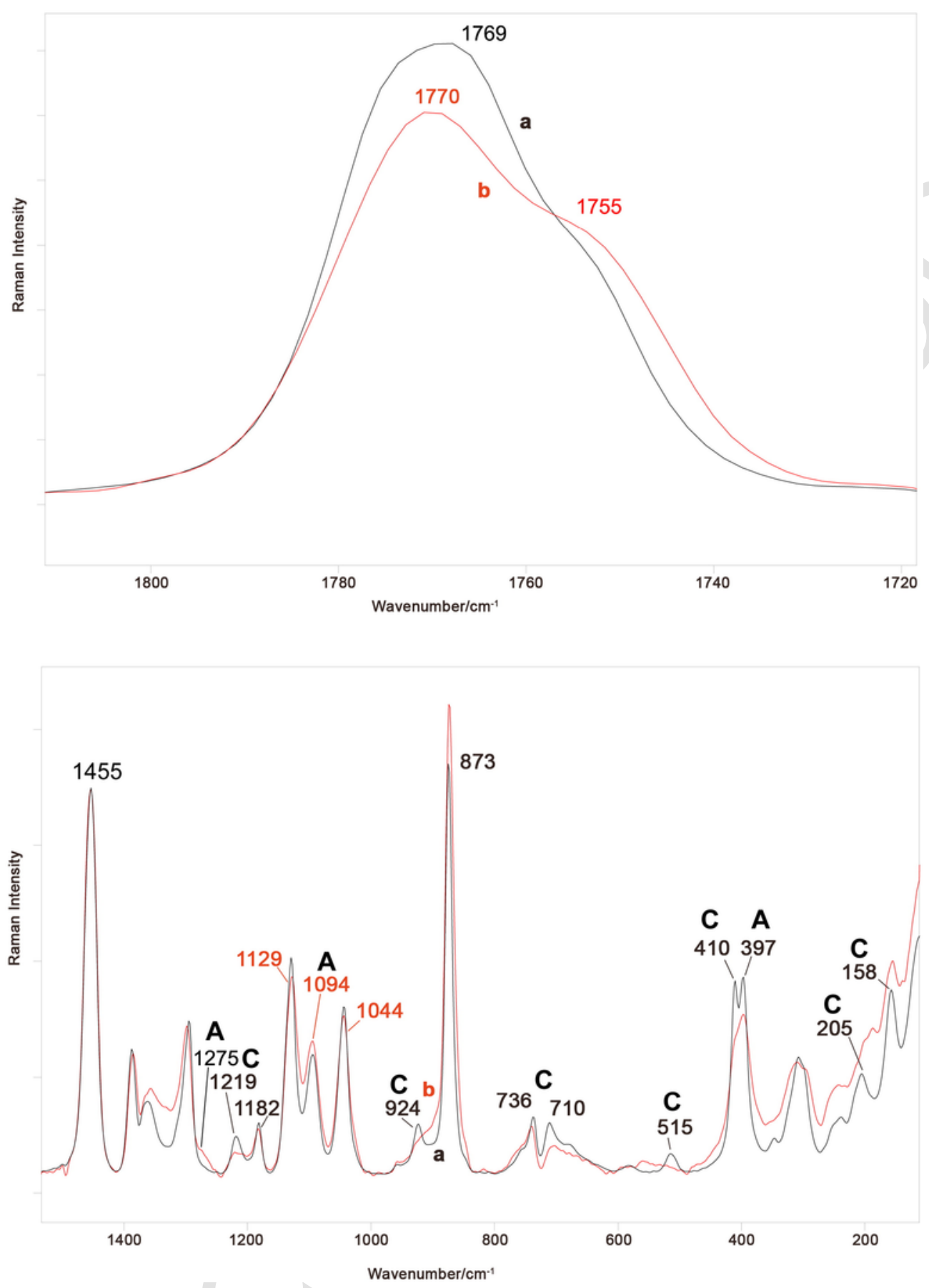

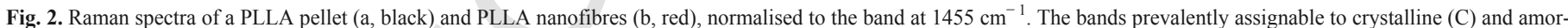
phous (A) PLLA are indicated. (For interpretation of the references to colour in this figure legend, the reader is referred to the web version of this article.)

conformers (tt't and tg't), consistently with an increase in the amorphous character, since the amorphous phase has been reported to contain about $80 \%$ of tg't conformers [33].

The $\alpha$-crystal marker band [29] at $924 \mathrm{~cm}^{-1}$ was observed only in the spectrum of the pellet. The $\mathrm{I}_{924} / \mathrm{I}_{873}$ intensity ratio can be considered a marker of crystallinity [34], since the band at $873 \mathrm{~cm}^{-1}$ has been reported to be insensitive to crystallinity [35].

The trend of the spectra below $800 \mathrm{~cm}^{-1}$ confirms the lower crystallinity of the nanofibres. The spectrum of the pellet showed the marker bands of crystallinity [29,35,36] at about 710, 515, 410-397, 205 and $158 \mathrm{~cm}^{-1}$ as more intense and distinct.
The DSC thermograms of the PLLA pellet and nanofibres (see Fig. S1, Supplementary material) confirmed the morphology differences revealed by spectroscopic analyses. The DSC thermogram of the pellet showed a glass transition at $65^{\circ} \mathrm{C}$, a small exothermic peak at $155^{\circ} \mathrm{C}$, identified as characteristic of the $\alpha^{\prime}$ phase and due to the $\alpha^{\prime} \rightarrow \alpha$ phase transition [37], followed by an endothermic melting peak at $169{ }^{\circ} \mathrm{C}$. According to Eq. (1), a $\mathrm{X}_{\mathrm{c}} \%$ of $44 \%$ was calculated for the pellet. The DSC thermogram of PLLA nanofibres confirmed that upon electrospinning a less ordered crystalline state was obtained; actually, the nanofibres displayed a double glass transition [38], a crystallisation peak at $83^{\circ} \mathrm{C}$, an $\alpha^{\prime} \rightarrow \alpha$ phase transition at 
$148^{\circ} \mathrm{C}$ and a broadened and double melting peak with components at 163 and $165^{\circ} \mathrm{C}$. The first $\mathrm{T}_{\mathrm{g}}$ at about $60^{\circ} \mathrm{C}$ had a typical glass transition behaviour, appearing as a baseline inflection to the endothermic side; the second $\mathrm{T}_{\mathrm{g}}$, at $67^{\circ} \mathrm{C}$, which looked like an endothermic crystalline melting peak, has been attributed to the enthalpy stress-relaxation effect [39]. These features, together with the appearance of a large exothermic crystallisation peak and the shift of the melting peak to lower temperatures, confirmed the less ordered state of the PLLA nanofibres. Moreover, the broadening of the melting peak showed that differently sized crystallites were present. These qualitative results were quantitatively confirmed by the $\mathrm{X}_{\mathrm{c}} \%$ value that decreased to $19 \%$.

These trends suggest that the conditions used in the electrospinning process allowed a rearrangement of the polymeric chains (which became unordered upon solubilisation in TFA) towards an ordered state, although the crystallinity degree of the pellet was not recovered.

\subsection{Vibrational and thermal analyses on $S F$ powder and nanofibres}

Figs. S2 and S3 show the Raman and IR spectra, respectively, of the regenerated SF powder and nanofibres after immersion in methanol solution (see Tables S1 and S2, Supplementary material for assignments). The spectra of $B$. mori silk fibroin fibres are reported for comparison. All the samples had a prevailing $\beta$-sheet conformation, as mainly attested by the position of the Amide I, II and III bands (Tables S1 and S2, Supplementary material).

Going from the fibres to the powder, the $\beta$-sheet content decreased; actually, the bands characteristic of this structure (at 1085, 978 and $883 \mathrm{~cm}^{-1}$ in Raman [40-44] and at about 1700, 1065, 975 and $1000 \mathrm{~cm}^{-1}$ in IR [45-48]) weakened and the NH stretching region underwent some changes. Moreover, the Raman $\mathrm{I}_{1232} / \mathrm{I}_{1264}$ intensity ratio, commonly used as a marker of the $\beta$-sheet content, decreased from 1.80 to 1.26 . Going from the fibres to the powder, the $\mathrm{I}_{850} / \mathrm{I}_{830}$ Raman intensity ratio, widely used to describe the average hydrogen-bonding state of tyrosine $[42,49]$, increased from 1.45 to 1.81 , suggesting a change of the average Tyr environment towards a prevalently hydrogen bonding acceptor.

The $\beta$-sheet content in the nanofibres appeared higher than in the powder: with respect to this sample, the $\mathrm{I}_{1232} / \mathrm{I}_{1264}$ Raman intensity ratio increased to 1.33 . This result indicates that the native structural characteristics of SF were preserved in the solubilisation/electrospinning process, since the treatment with methanol solution induced the expected $\beta$-sheet transformation [26].

A band at $1728 \mathrm{~cm}^{-1}$ appeared in both the Raman and IR spectra of the nanofibres, suggesting the protonation of the glutamate (Glu) and aspartate (Asp) residues, upon dissolution in TFA $\left(\mathrm{pK}_{\mathrm{a}}=0.2\right)$, in agreement with previous investigations [50,51]. As a result of the protonation, the Raman band observed at $1410 \mathrm{~cm}^{-1}$ in the spectrum of the SF powder shifted to $1405 \mathrm{~cm}^{-1}$ in the SF nanofibres, due to the loss of the contribution to the antisymmetric $\mathrm{COO}^{-}$stretching of deprotonated Asp Glu residues. Analogously, the IR band at $1404 \mathrm{~cm}^{-1}$ weakened. Deprotonation may also explain the shift of the IR $\mathrm{NH}_{3}^{+}$ stretching to higher wavenumber; this behaviour may be ascribed to the weakening of ionic coupling interactions, due to the decrease of the amount of $\mathrm{COO}^{-}$groups. Going from the SF powder to the nanofibres, the $\mathrm{I}_{850} / \mathrm{I}_{830}$ increased from 1.81 to 1.97 , suggesting a change in the tyrosine average environment towards a more exposed state. This behaviour may be explained also in relation to the presence of protonated Asp and Glu residues, which may act as hydrogen bond donors.
DSC analysis confirmed the structural differences observed between the SF powder and the nanofibres. (Fig. S4, Supplementary material). The DSC thermogram of the SF powder showed a glass transition at $185^{\circ} \mathrm{C}$, an exotherm crystallisation by random coil $\rightarrow \beta$-sheet conformational transition at $209^{\circ} \mathrm{C}$ and a thermal decomposition at $287^{\circ} \mathrm{C}$. In the thermogram of the SF nanofibres, the $\mathrm{T}_{\mathrm{g}}$ transition observed at about $200{ }^{\circ} \mathrm{C}$ was not followed by the above observed crystallisation peak. Moreover, the maximum of the decomposition peak downshifted to $276{ }^{\circ} \mathrm{C}$, i.e. a temperature typical of amorphous silk fibroin [52], and shoulders at 280, 284 and $295^{\circ} \mathrm{C}$ were detected; an additional peak at $302{ }^{\circ} \mathrm{C}$ was observed. It must be noted that $\beta$-sheet decomposition has been reported to occur at about $290-300{ }^{\circ} \mathrm{C}$ [53].

\subsection{Effect of blending: spectroscopic and thermal analyses of SF/ PLLA nanofibres}

Figs. 3 and 4 show the IR and Raman spectra, respectively, of SF, PLLA and SF/PLLA nanofibres. In both IR and Raman spectra of the composite nanofibres, some bands are prevalently ascribable to the SF component, others to the PLLA component, as detailed in Tables S1 and S2, Supplementary material.

Upon blending with the SF component, the $\iota \mathrm{C}=\mathrm{O}$ stretching band of PLLA shifted and changed its width in both IR and Raman spectra (Figs. 3 and 4). The IR marker bands of the crystalline phase at about 1360,1300 and $870 \mathrm{~cm}^{-1}$ weakened with respect to the PLLA nanofibres, suggesting a slight decrease in the polymer crystallinity; this result was confirmed by the decrease of the Raman $\mathrm{I}_{1129} / \mathrm{I}_{1044}$ intensity ratio from 1.20 to 0.98 .

The IR and Raman Amide I and NH stretching bands of the SF component in the composite underwent-

Some changes in position and FWHM upon mixing with PLLA. Although these trends would suggest structural rearrangements, the main conformation remained $\beta$-sheet, as revealed by the IR spectral features at 1698,1000 and $975 \mathrm{~cm}^{-1}$ and by the Raman $\mathrm{I}_{1229} / \mathrm{I}_{1265}$ intensity ratio which attained the same value as in the SF nanofibres (i.e. 1.33). The changes observed in the $\mathrm{C}=\mathrm{O}$ PLLA stretching mode may be explained both in term of a decreased crystallinity and also in relation to the changes observed in the NH stretching of SF in both IR and Raman spectra (Figs. 3 and 4). These trends allowed to hypothesise the occurrence of hydrogen bonds rearrangements upon formation of $\mathrm{C}=\mathrm{O}^{\cdots} \mathrm{H}-\mathrm{N}$ hydrogen bonds between PLLA and SF, without excluding the possibility of the involvement of other SF side-chain groups. The constancy of the $\beta$-sheet content would suggest that these rearrangements mainly involved amorphous domains of SF. Therefore, also in presence of PLLA, the native structural characteristics of SF were not lost in the electrospinning process, since the SF ability to adopt a $\beta$-sheet conformation upon treatment with methanol solution was preserved.

The trend of the DSC thermogram of SF/PLLA nanofibres (Fig. S5, Supplementary material) confirmed the structural rearrangements observed by spectroscopic analyses.

The $\mathrm{X}_{\mathrm{c}} \%$ of the PLLA component slightly changed upon blending with $\mathrm{SF}$, decreasing to $17 \%$. The thermal features observed in the thermogram of the SF/PLLA nanofibres showed that the polymeric chains underwent structural rearrangements when electrospun in presence of the SF component. In fact, a $\mathrm{T}_{\mathrm{g}}$ peak (superimposed to the endothermal water evaporation) at $67^{\circ} \mathrm{C}$ was observed and, differently from the thermogram of the PLLA nanofibres, no exothermic crystallisation peak was revealed. This result indicates that upon blending, the thermally induced rearrangement of PLLA chains into more ordered clusters was hindered (i.e. they became unable to crys- 

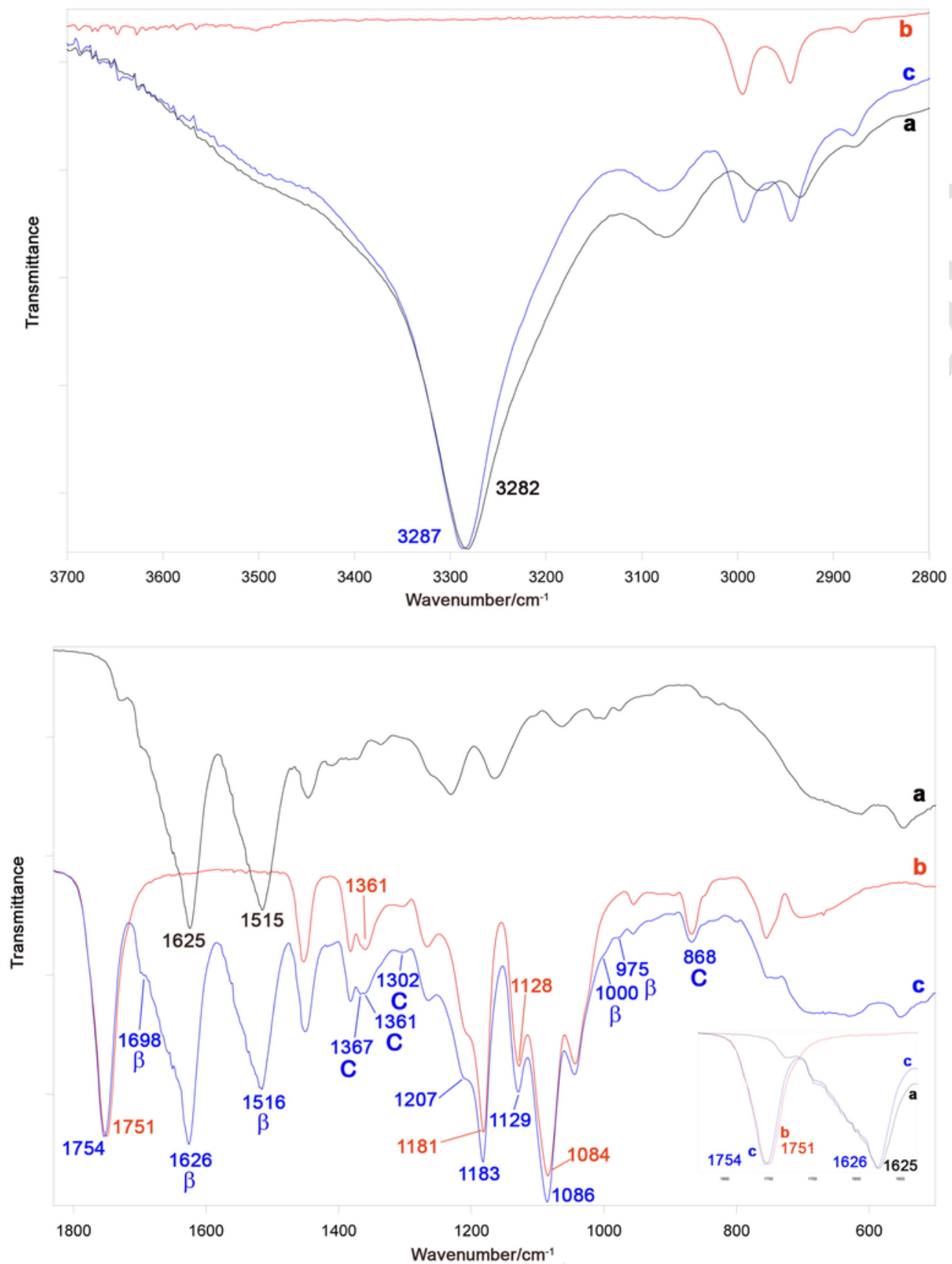

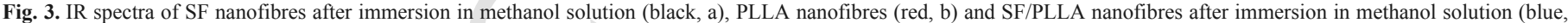
c). (For interpretation of the references to colour in this figure legend, the reader is referred to the web version of this article.)

tallise). The DSC thermogram of the SF/PLLA nanofibres showed a $\mathrm{T}_{\mathrm{g}}$ transition of the $\mathrm{SF}$ component at $202^{\circ} \mathrm{C}$, followed by a very small exotherm crystallisation at $231^{\circ} \mathrm{C}$ and a thermal decomposition at $279^{\circ} \mathrm{C}$. The $\beta$-sheet decomposition was covered by the PLLA decomposition, which appeared shifted from $322^{\circ} \mathrm{C}$ to $316^{\circ} \mathrm{C}$ going from the PLLA nanofibres to the SF/PLLA nanofibres.

The DSC data showed that the SF and PLLA components had a different thermal behaviour in the composite with respect to the pure SF and PLLA nanofibres. On the other hand, experimental and calculated spectra (Fig. S6, Supplementary material) showed several differences both in Raman and IR. These findings suggested that the SF and PLLA components were thermodynamically compatible rather than phase separated. The differences in the wavenumber position, width and relative intensity of several bands between the experimental and calculated spectra (Fig. S6, Supplementary material) indicated that intermolecular interactions (mainly hydrogen bonding) occurred between the two components. These interactions modified the structural arrangements of SF and PLLA, without altering the ability of SF to adopt $\beta$-sheet structure. From this point of view, the SF/PLLA nanofibres under study were significantly different with respect to the composite $A$. pernyi (Tussah) silk fibroin/PLLA nanofibres obtained by $\mathrm{He}$ et al. [22] for which phase separation and decrease of the $\beta$-sheet content was observed at PLLA percentages higher than $10 \%$. Moreover, the SF component appeared more suitable than chitosan in the preparation of blended PLLA-containing nanofibres. Xu et al. 

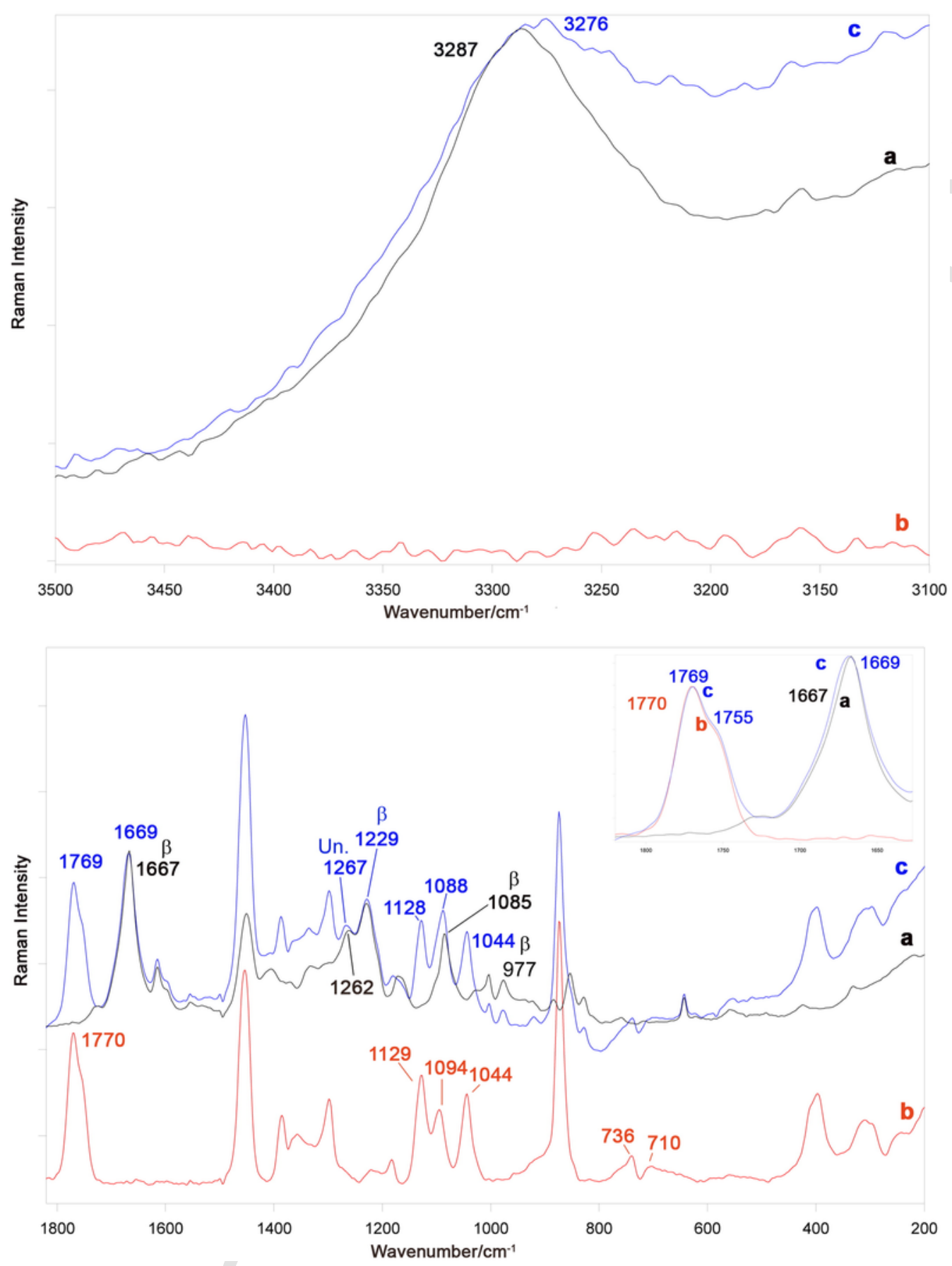

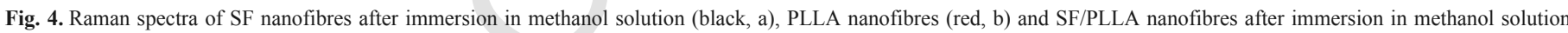
(blue, c). (For interpretation of the references to colour in this figure legend, the reader is referred to the web version of this article.)

have reported that molecular interactions between chitosan and PLLA were very weak [54].

The occurrence of hydrogen bond interactions between SF and PLLA was demonstrated for the first time in the present study. Zhu et al. have only speculated the formation of such hydrogen bond interactions in SF/PLLA blended films [11]. However, these authors have reported a loss of tensile strength when the PLLA content increased from 7 to $10 \%$ as a result of a reduced interaction between the two phases. At this purpose, it is interesting to note that in our SF/PLLA nanofibres hydrogen bond interactions persist also at PLLA contents as high as $50 \%$. No obvious chemical bond reaction between SF and PLLA-CL has been reported in SF/PLLA-CL nanofibrous scaffolds [18] and phase separation has been shown when SF was electrospun with poly(ethylene oxide [19]) and in SF/PLLA-PEG-PLLA hydrogels [13].

Our data showed that hydrogen bond interactions caused a structural rearrangement of the PLLA component towards a slightly less ordered state. Actually, the Raman $\mathrm{I}_{1129} / \mathrm{I}_{1044}$ ratio was slightly higher in the calculated spectrum than in the experimental one $\left(\mathrm{I}_{1129} / \mathrm{I}_{1044}=1.03\right.$ versus 0.98), showing that the real spectrum sug- 
gests a higher amorphous character for the PLLA component than the theoretical one. Moreover, the IR experimental spectrum displayed a higher intensity for the bands assigned to amorphous PLLA than the calculated spectrum (in particular, those at 1183 and $1086 \mathrm{~cm}^{-1}$ ) and displayed a lower intensity of the bands ascribed to crystalline PLLA (in particular, those at 1367, 1302, 1207, 1129 and $868 \mathrm{~cm}^{-1}$ ). The spectroscopic and thermal results showed that in the SF/PLLA nanofibres, the crystallisation of PLLA was slightly hindered by the presence of SF. SF preferentially crystallises and its crystallisation occurs prior to that of PLLA.

\subsection{Morphological analysis: scanning electron microscopy}

Fig. 5 reports SEM images of PLLA, SF and SF/PLLA nanofibres and the analysis of fibre and pore diameter size distribution. Membranes with randomly distributed nanofibres were obtained for all the samples. PLLA nanofibres (Fig. 5 A-A') did not show morphological defects. On the other hand, in the case of SF/PLLA (Fig. $5 \mathrm{C}^{-\mathrm{C}^{\prime}}$ ) and SF nanofibres (Fig. 5 B-B'), a few areas with partial fibre collapse were observed, probably due to fibre swelling during the immersion step in methanol solution. SF, PLLA and SF/PLLA nanofibres showed average nanofibre sizes of $360 \pm 90 \mathrm{~nm}, 470 \pm 240 \mathrm{~nm}$ and $580 \pm 220 \mathrm{~nm}$, respectively. The distribution of SF nanofibre diame- ters $(200-400 \mathrm{~nm})$ was narrower than for SF/PLLA $(200-1000 \mathrm{~nm})$ and PLLA (200-800 nm) nanofibres (Fig. 5D). On the other hand, pore size distribution was not affected by the materials used to produce the nanofibrous membranes: more than $50 \%$ of the pores were of $1-2 \mu \mathrm{m}$ size and around $30-40 \%$ were of lower size than $1 \mu \mathrm{m}$ (Fig. $5 \mathrm{E})$. This result suggests that cells cannot penetrate into the electrospun substrates, in the first phases of cell proliferation, at least.

\subsection{AFM imaging}

Fig. 6 shows AFM perspective views of SF, SF/PLLA and PLLA networks. AFM micrographs showed that SF nanofibres were of lower size as compared to SF/PLLA and PLLA nanofibres, in agreement with SEM analysis. Table S3, Supplementary material reports the average $\mathrm{Rq}$ roughness values measured on the nanofibres under study; the data showed that SF nanofibres had the highest average roughness, but also the highest associated standard deviation.

As also evident in Fig. S7, Supplementary material, the AFM imaging shows some small surface features on the top of globally flat round fibres. Higher resolution topographic images were obtained only for the top portion of the fibres as the AFM probe cannot scan properly the sides of such high-aspect ratio objects. Recorded surface features are often ridges arranged longitudinally to the fibre direction,
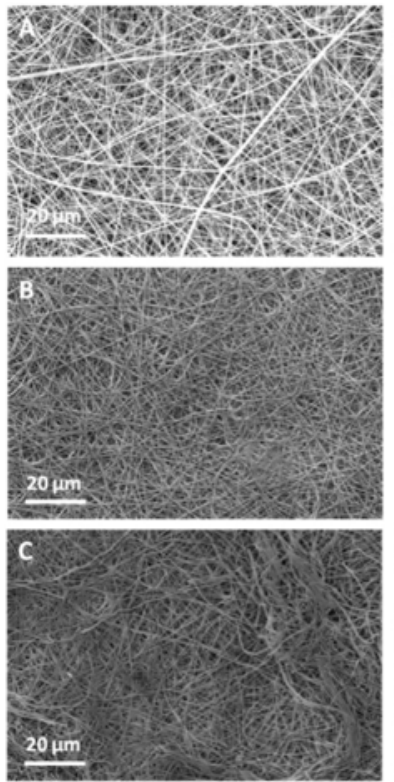
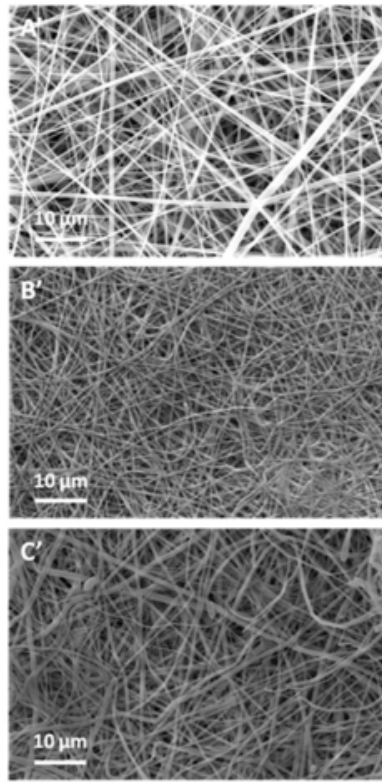

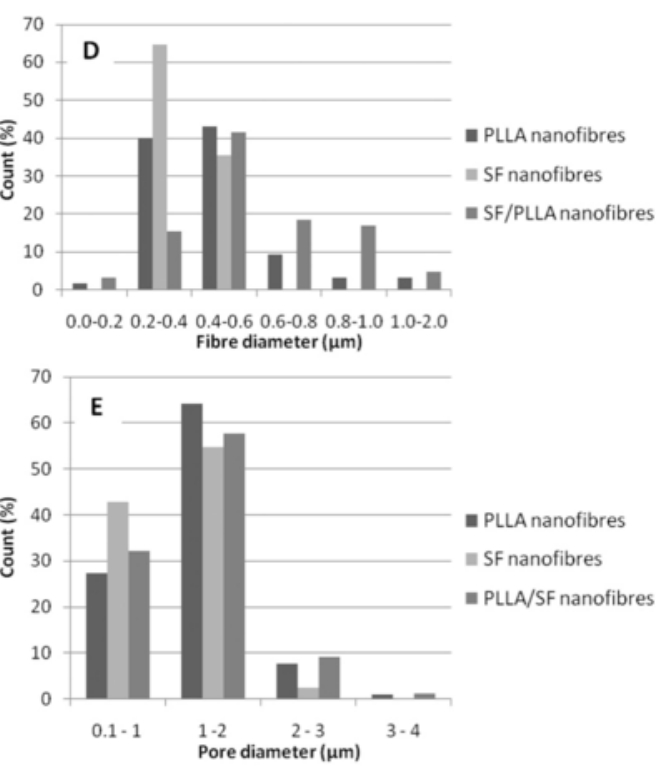

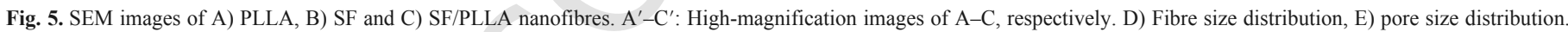
Fibre diameters were reported as average value \pm standard deviation.

A

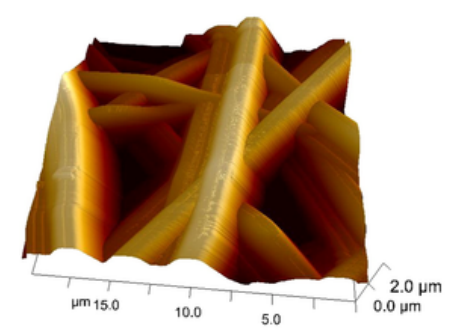

B

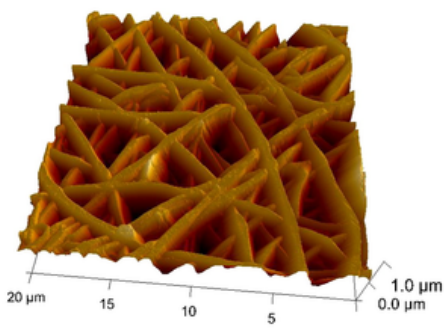

C

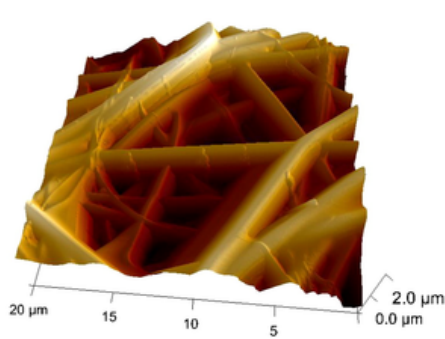

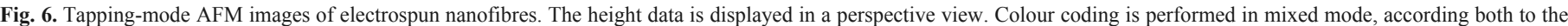
features heights and to artificial illumination that can enhance the contrast of surface features. (A) PLLA fibres, (B) SF fibres, (C) SF/PLLA fibres. 
or sometimes perpendicularly to it. These could be likely attributed to the spinning procedure or the possible fibre relaxation subsequent to the spinning event. Occasionally, some small irregular bumps were detected on the surface of the fibres (see Fig. S7, Supplementary material for one example surface scan on a SF/PLLA fibre).

Phase imaging did not show any apparent surface domains with measurably different surface properties on any of the fibres types that were imaged. The lack of evident surface domains of different mechanical properties in the phase imaging of SF/PLLA fibres can be attributed to the high compatibility between SF and PLLA.

\subsection{Cellular proliferation and cytotoxicity tests}

Fig. 7 shows the cellular proliferation determined by crystal violet assay (A) and cytotoxicity assayed by calcein-AM assay (B) of keratinocytes exposed to SF, PLLA and SF/PLLA nanofibres for $24 \mathrm{~h}$. Cell proliferation evaluated by crystal violet assay shows as the presence of SF in SF/PLLA composite nanofibres increases the ability of cells to adhere to the material and to grow. The SF component appears to enhance the cell viability of keratinocytes, if compared to their unfunctionalised counterpart, as assessed by calcein-Am assay.

The improvement of proliferation and absence of cytotoxicity (indeed the observed increased viability) on the composite SF/PLLA
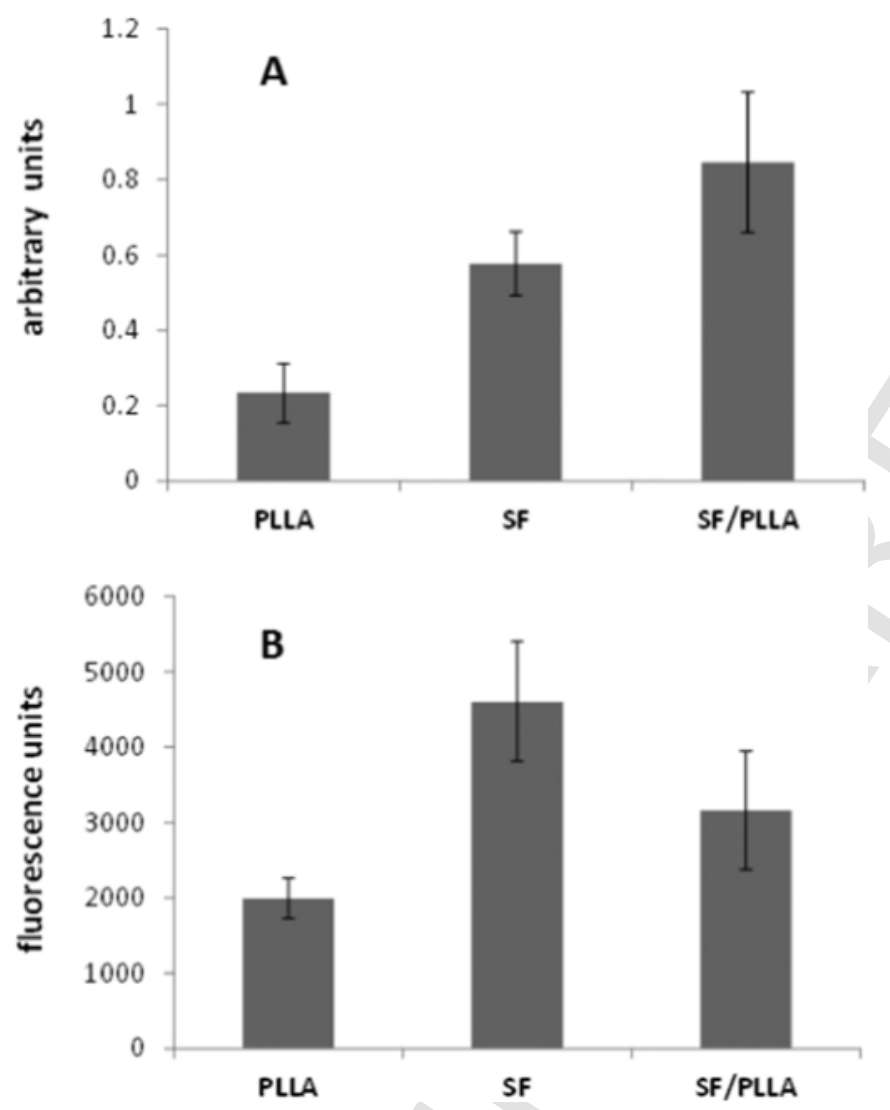

Fig. 7. Cellular viability determined by crystal violet assay (A) and calcein-AM assay (B) of keratinocytes exposed to SF, PLLA and SF/PLLA nanofibres for $24 \mathrm{~h}$. (For interpretation of the references to celour in this fioure legend, the reader is referred to the web version of this article.) nanofibres may be attributed to the interactions between SF and cells, which evidently have found a more advantageous microenvironment on the composite nanofibres surface than on PLLA. It is well known that the material surface properties (i.e. chemical composition, hydrophilicity, roughness, porosity) have a great influence on cell adhesion and growth. Lv et al. [12] have observed an increase in human hepatocellular liver carcinoma cell attachment upon:

Incorporation of insoluble SF microparticles into a PLLA film. Actually, a SF substratum has been reported to promote the growth of anchorage dependent mammalian cells, thanks to its hydrophilic nature as well as to its ability to interact with the negative charged surface of cell membrane [55]. On the contrary, aliphatic polyesters, such as PLLA, have poor hydrophilic properties and lack bioactivity and cell affinity. Therefore, the incorporation of SF into the SF/PLLA composite nanofibres definitely improved hydrophilicity with respect to pure PLLA. In general, hydrophilic surfaces display a better affinity for cells, but lower absorption for proteins than hydrophobic surfaces [56].

Cai et al. have reported a better osteoblast adhesion and growth on composite SF/poly(D,L-lactic acid) (PDLLA) composite films than on pure PDLLA films [57]. The authors have related this phenomenon to the enrichment in nitrogen obtained upon incorporation of SF into PDLLA, i.e. to the chemical composition of SF. SF has (Ala-Gly) n repeated sequences which would be present onto the outermost surface of the PDLLA film, thus affecting cell growth. Our results may be explained accordingly and would suggest that the interactions occurring between SF and PLLA, as revealed by vibrational spectroscopy, did not prevent the natural cell recognition sites of SF from being exposed towards the surface of the composite nanofibres.

\section{Conclusions}

B. mori SF/PLLA randomly oriented nanofibrous membranes were successfully produced by electrospinning together with pure SF and PLLA nanofibrous membranes. SF, PLLA and SF/PLLA nanofibres showed an average size of $360 \pm 90 \mathrm{~nm}, 470 \pm 240 \mathrm{~nm}$ and $580 \pm 220 \mathrm{~nm}$, respectively.

The PLLA nanofibres had a halved crystallinity degree with respect to the starting PLLA pellets. Upon blending with SF, both SF and PLLA components underwent structural rearrangements. The PLLA component decreased its degree of crystallinity, the SF component underwent conformational changes that did not significantly alter its prevailing $\beta$-sheet structure, suggesting that the electrospinning process did not alter the native structural characteristics of SF. The spectroscopic and thermal data suggest that in the SF/PLLA nanofibres, the crystallisation of PLLA was slightly hindered by the presence of SF; the SF and PLLA components were thermodynamically compatible and the occurrence of intermolecular interactions was demonstrated for the first time in the present study.

Preliminary cell culture results showed that the surface of the nanofibres was compatible with keratinocytes attachment and proliferation. The incorporation of the SF component into PLLA enhanced the properties of the unfunctionalised material. SF has been successfully used to modify the biomaterial properties and its use confirmed as an efficient way to enhance the cell affinity of a biomaterial. The reported results open the way towards future biomedical applications. 

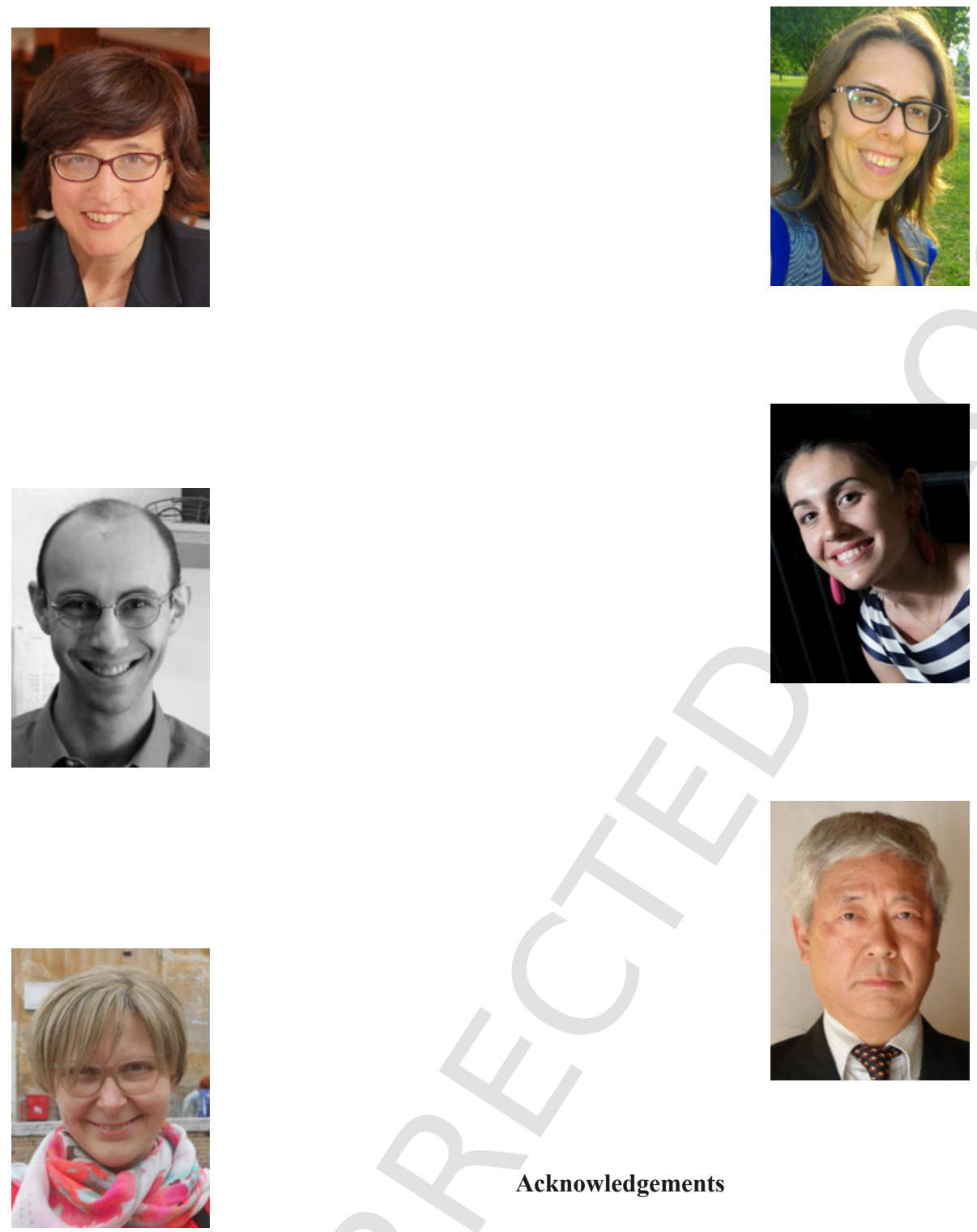

\section{Acknowledgements}

This work was supported by RFO funds from University of Bologna.

\section{Appendix A. Supplementary data}

Supplementary data to this article can be found online at http://dx.

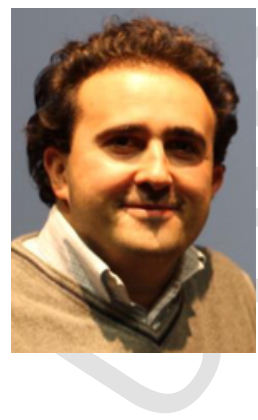
doi.org/10.1016/j.msec.2016.09.055.

\section{References}

[1] C. Vepari, L. Kaplan D, Silk as a biomaterial, Prog Polym Sci 32 (2007) 991-1007.

[2] J. Melke, S. Midha, S. Ghosh, K. Ito, S. Hofmann, Silk fibroin as biomaterial for bone tissue engineering, Acta Biomater. 31 (2016) 1-16.

[3] S. Kapoor, S.C. Kundu, Silk protein-based hydrogels: promising advanced materials for biomedical applications, Acta Biomater. 31 (2016) 17-32.

[4] G. Li, Y. Li, G. Chen, J. He, Y. Han, X. Wang, D.L. Kaplan, Silk-based biomaterials in biomedical textiles and fiber-based implants, Adv Healthcare Mater 4 (2015) 1134-1151. 
[5] C.S. Ki, W.J. Kim, H.J. Hyun, H.K. Lee, M. Hattori, K.D. Rah, H.Y. Park, Electrospun three-dimensional silk fibroin nanofibrous scaffold, J. Appl. Polym. Sci. 106 (2007) 3922-3928.

[6] S. Zarkoob, R.K. Eby, D.H. Reneker, S.D. Hudson, D. Ertley, W.W. Adams, Structure and morphology of electrospun silk nanofibers, Polymer 45 (2004) 3973-3977.

[7] S.Y. Park, C.S. Ki, Y.H. Park, H.M. Jung, K.M. Woo, H.J. Kim, Electrospun silk fibroin scaffolds with macropores for bone regeneration: an in vitro and in vivo study, Tissue Eng Part A 16 (2010) 1271-1279.

[8] G.Y. Bo, Y.Z. Zhu, W.S. Dong, S.D. Bing, D.Z. Hui, F.W. Guo, Study of the electrospun PLA/silk fibroin-gelatin composite nanofibrous scaffold for tissue engineering, J. Biomed. Mater. Res. 93A (2010) 158-163.

[9] S. Wang, Y. Zhang, H. Wang, G. Yin, Z. Dong, Fabrication and properties of the electrospun polylactide/silk fibroin-gelatin composite tubular scaffold, Biomacromolecules 10 (2009) 2240-2244.

[10] A. Chiarini, P. Petrini, S. Bozzini, I. Dal Pra, U. Armato, Silk fibroin/poly(carbonate)-urethane as a substrate for cell growth: in vitro interactions with human cells, Biomaterials 24 (2003) 789-799.

[11] H. Zhu, X. Feng, H. Zhang, Y. Guo, J. Zhang, J. Chen, Structural characteristics and properties of silk fibroin/poly(lactic acid) blend films, J Biomater Sci Polymer Ed 20 (2009) 1259-1274.

[12] Q. Lv, K. Hu, Q. Feng, F. Cui, C. Cao, Preparation and characterization of PLA fibroin composite and culture of HepG2 (human hepatocellular liver carcinoma cell line) cells, Compos. Sci. Technol. 67 (2007) 3023-3030.

[13] T. Zhong, C. Deng, Y. Gao, M. Chen, B. Zuo, Studies of in situ-forming hydrogels by blending PLA-PEG-PLA copolymer with silk fibroin solution, J. Biomed. Mater. Res. 100A (2012) 1983-1989.

[14] H.W. Ju, F.A. Sheikh, B.M. Moon, H.J. Park, O.J. Lee, J.H. Kim, J.J. Eun, G. Khang, C.H. Park, Fabrication of poly(lactic-co-glycolic acid) scaffolds containing silk fibroin scaffolds for tissue engineering applications, J Biomed Mater Res 102A (2014) 2713-2724. 2014.

[15] M. Stoppato, H.Y. Stevens, E. Carletti, C. Migliaresi, A. Motta, R.E. Guldberg, Effects of silk fibroin fiber incorporation on mechanical properties, endothelial cell colonization and vascularization of PDLLA scaffolds, Biomaterials 34 (2013) 4573-4581.

[16] J.S. Bergström, D. Hayman, An overview of mechanical properties and material modeling of polylactide (PLA) for medical applications, Ann. Biomed. Eng. 44 (2016) 330-340.

[17] B.D. Ulery, L.S. Nair, C.T. Laurencin, Biomedical applications of biodegradable polymers, Polym Sci B Polym Phys 49 (2011) 832-864.

[18] K. Zhang, H. Wang, C. Huang, Y. Su, X. Mo, Y. Ikada, Fabrication of silk fibroin blended P(LLA-CL) nanofibrous scaffolds for tissue engineering, J. Biomed. Mater. Res. 93A (2010) 984-993.

[19] H.J. Jin, S.V. Fridrikh, G.C. Rutledge, D.L. Kaplan, Electrospinning Bombyx mori silk with poly(ethylene oxide), Biomacromolecules 3 (2002) 1233-1239.

[20] S. Sahoo, S.L. Toh, J. Cho, H. Goh, PLGA nanofiber-coated silk microfibrous scaffold for connective tissue engineering, J. Biomed. Mater. Res. 95B (2010) 19-28.

[21] Y.I. Yoon, K.E. Park, S.J. Lee, W.H. Park, Fabrication of microfibrous and nano-/microfibrous scaffolds: melt and hybrid electrospinning and surface modification of poly(L-lactic acid) with plasticizer, Biomed. Res. Int. 309048 (2013) $1-10$.

[22] J. He, Y. Qin, S. Cui, Y. Gao, S. Wang, Structure and properties of novel electrospun tussah silk fibroin/poly(lactic acid) composite nanofibers, J. Mater. Sci. 46 (2011) 2938-2946.

[23] K. Shanmugam, S. Sundaramoorthy, Development and characterization of an electrospun mat from Eri silk fibroin and PLA blends for wound dressing application, RSC Adv 5 (2015) 31352-31364.

[24] Q. Yu, C. Sun, A three-dimensional multiporous fibrous scaffold fabricated with regenerated spider silk protein/poly(L-lactic acid) for tissue engineering, J. Biomed. Mater. Res. 103A (2015) 721-729.

[25] L. Tian, M.P. Prabhakaran, J. Hu, M. Chen, F. Besenbacher, S. Ramakrishna, Coaxial electrospun poly(lactic acid)/silk fibroin nanofibers incorporated with nerve growth factor support the differentiation of neuronal stem cells, RSC Adv. 5 (2015) 49838-49848.

[26] M. Tsukada, Y. Gotoh, M. Nagura, N. Minoura, N. Kasai, G. Freddi, Structural changes of silk fibroin membranes induced by immersion in methanol aqueous solutions, J. Polym. Sci. Polym. Phys. 32 (1994) 961-968.

[27] E. Ranzato, M. Patrone, L. Mazzucco, B. Burlando, Platelet lysate stimulates scratch wound repair of HaCaT keratinocytes, Br J Dermatol 159 (2008) $537-545$.

[28] S. Martinotti, E. Ranzato, M. Parodi, M. Vitale, B. Burlando, Synergistic combination of ascorbate/gemcitabine/epigallocatechin-3-gallate induces cell cycle deregulation and apoptosis in mesothelioma cells, Toxicol. Appl. Pharmacol. 274 (2014) 35-41.

[29] G. Kister, G. Cassanas, M. Vert, B. Pauvert, A. Térol, Vibrational analysis of poly(L-lactic acid), J. Raman Spectrosc. 26 (1995) 307-311.
[30] J.M. Zhang, H. Tsuji, I. Noda, Y. Ozaki, Weak intermolecular interactions during the melt crystallization of poly(L-lactide) investigated by two-dimensional infrared correlation spectroscopy, J. Phys. Chem. B 108 (2004) 11514-11520.

[31] D. Qin, R.T. Kean, Crystallinity determination of polylactide by FT-Raman spectrometry, Appl. Spectrosc. 52 (1998) 488-495.

[32] X. Yang, S. Kang, Y. Yang, K. Aou, S.L. Hsu, Raman spectroscopic study of conformational changes in the amorphous phase of poly(lactic acid) during deformation, Polymer 45 (2004) 4241-4248.

[33] X. Yang, S. Kang, S.L. Hsu, H.D. Stidham, P.B. Smith, A.A. Leugers, A spectroscopic analysis of chain flexibility of poly(lactic acid), Macromolecules 34 (2001) 5037-5041.

[34] V. Guarino, F. Causa, P. Taddei, M. Di Foggia, G. Ciapetti, D. Martini, C. Fagnano, N. Baldini, L. Ambrosio, Polylactic acid fibre reinforced polycaprolactone scaffolds for bone tissue engineering, Biomaterials 29 (2008) 3662-3670.

[35] P.B. Smith, A. Leugers, S. Kang, S.L. Hsu, X. Yang, An analysis of the correlation between structural anisotropy and dimensional stability for drawn poly(lactic acid) films, J. Appl. Polym. Sci. 82 (2001) 2497-2505.

[36] S. Kang, S.L. Hsu, H.D. Stidham, P.B. Smith, M.A. Leugers, X. Yang, A spectroscopic analysis of poly(lactic acid) structure, Macromolecules 34 (2001) 4542-4548.

[37] J. Zhang, K. Tashiro, H. Tsuji, A.J. Domb, Disorder-to-order phase transition and multiple melting behavior of poly(-lactide) investigated by simultaneous measurements of WAXD and DSC, Macromolecules 41 (2008) 1352-1357.

[38] G.W. Park, Degradation of poly(lactic-co-glycolic acid) microspheres: effect of copolymer composition, Biomaterials 16 (1995) 1123-1130.

[39] D. Cam, S.H. Hyon, Y. Ikada, Degradation of high molecular weight poly(L-lactide) in alkaline medium, Biomaterials 16 (1995) 833-843.

[40] P. Monti, G. Freddi, A. Bertoluzza, N. Kasai, M. Tsukada, Raman spectroscopic studies of silk fibroin from Bombyx mori, J. Raman Spectrosc. 29 (1998) 297-304.

[41] H.G.M. Edwards, D.W. Farwell, Raman spectroscopic studies of silk, J. Raman Spectrosc. 26 (1995) 901-909.

[42] P. Taddei, T. Asakura, J. Yao, P. Monti, Raman study of poly(alanine-glycine)-based peptides containing tyrosine, valine and serine as model for the semi-crystalline domains of Bombyx mori silk fibroin, Biopolymers 75 (2004) 314-324.

[43] P. Monti, P. Taddei, G. Freddi, T. Asakura, M. Tsukada, Raman spectroscopic characterization of Bombyx mori silk fibroin: Raman spectrum of silk I, J. Raman Spectrosc. 32 (2001) 103-107.

[44] P. Taddei, V. Chiono, A. Anghileri, G. Vozzi, G. Freddi, G. Ciardelli, Silk fibroin/gelatin blend films crosslinked with enzymes for biomedical applications, Macromol. Biosci. 13 (2013) 1492-1510.

[45] J. Magoshi, Y. Magoshi, Physical properties and structure of silk. II. Dynamic mechanical and dielectric properties of silk fibroin, J. Polym. Sci. Polym. Phys. Ed. 13 (1975) 1347-1351.

[46] P. Monti, P. Taddei, G. Freddi, K. Ohgo, T. Asakura, Vibrational, ${ }^{13}$ C-cross-polarization/magic angle spinning NMR spectroscopic and thermal characterization of poly(alanine-glycine) as model for silk I Bombyx mori fibroin, Biopolymers 72 (2003) 329-338.

[47] P. Taddei, P. Monti, Vibrational IR conformational studies of model peptides representing the semi-crystalline domains of Bombyx mori silk fibroin, Biopolymers 78 (2005) 249-258.

[48] W.H. Moore, S. Krimm, Vibrational analysis of peptides, polypeptides, and proteins. II. $\beta$-poly(L-alanine) and $\beta$-poly(L-alanylglycine), Biopolymers 15 (1976) 2465-2483.

[49] M.N. Siamwiza, R.C. Lord, M.C. Chen, T. Takamatsu, I. Harada, H. Matsuura, T. Shimanouchi, Interpretation of the doublet at 850 and $830 \mathrm{~cm}^{-1}$ in the Raman spectra of tyrosyl residues in proteins and certain model compounds, Biochemistry 14 (1975) 4870-4876.

[50] S.H. Kim, Y.S. Nam, T.S. Lee, W.H. Park, Silk fibroin nanofiber. Electrospinning, properties, and structure, Polym. J. 35 (2003) 185-190.

[51] P. Taddei, M. Tsukada, G. Freddi, Affinity of protein fibres towards sulphation, J. Raman Spectrosc. 44 (2013) 190-197.

[52] J. Magoshi, S. Nakamura, Studies on physical properties and structure of silk. Glass transition and crystallization of silk fibroin, J. Appl. Polym. Sci. 19 (1975) 1013-1015.

[53] H. Ishikawa, M. Tsukada, I. Toizume, A. Konda, K. Hirabayashi, DSC thermograms of silk fibroin, Sen'i Gakkaishi 28 (1972) 91-98.

[54] J. Xu, J. Zhang, W. Gao, H. Liang, H. Wang, J. Li, Preparation of chitosan/PLA blend micro/nanofibers by electrospinning, Mater. Lett. 63 (2009) 658-660.

[55] K. Inuvye, M. Shigemichi, N. Kewe, M. Tsukada, Use of Bombyx mori silk fibroin as a substratum of cultivation of animal cells, J. Biochem. Biophys. Methods 37 (1998) 159-164.

[56] M. Lampin, R. Warocquier-Clérout, L.M. Degrange, M.F. Sigot-Luizard, Correlation between substratum roughness and wettability, cell adhesion, and cell migration, J. Biomed. Mater. Res. 36 (1997) 99-108. 
[57] K. Cai, K. Yao, S. Lin, Z. Yang, X. Li, H. Xie, T. Qing, L. Gao, Poly(D.L-lactic acid) surfaces modified by silk fibroin: effects on the culture of osteoblast in vitro, Biomaterials 23 (2002) 1153-1160.

Paola Taddei, graduated in Chemistry in 1994, is Associate Professor of Biochemistry at the University of Bologna (Italy) since 2007. The scientific activity of Professor Paola Taddei, in cooperation with national and international scientific institutions, mainly concerns the chemical characterization (by vibrational spectroscopy and thermal analysis) of bioceramic and polymeric biomaterials in relation to their biocompatibility properties. Her most recent studies have focused on silk fibroin-based materials chemically modified for biomedical applications, the wear behaviour of ceramic and polyethylene prostheses for hip and knee joint replacement, the hydration mechanism and bioactivity of modified Portland cements for endodontic use.

Giampaolo Zuccheri is staff researcher and adjunct professor at the Department of Pharmacy and Biotechnologies of the University of Bologna, Italy. He received his master degree in 1994 from the Faculty of Industrial Chemistry of the University of Bologna and his Ph.D. in Chemistry in 1998 from the University of Calabria, Italy. He is coauthor of more than 45 peer-reviewed papers. His main interests lie in the biophysical characterization of biological macromolecules and in the development and applications of nucleic acids self-assembly. Some of his research activities include the development of microscopy characterization methods for biomaterials and macromolecules.

Simona Martinotti: The main focus of Dr. Simona Martinotti's research is the understanding of natural products effects in cancer cells, working at receptor, signal transduction and genomic levels. Another field of Dr. Martinotti's work concerns mechanisms in wound repair processes. Dr. Martinotti has provided a characterization of the mechanism of action of a platelet preparation that is currently used in clinical settings on an empirical basis. She has also observed the induction of epithelial-to-mesenchymal transition in keratinocytes under honey exposure, thus putting the basis for a pharmacological characterization of this old empirically remedy.

Elia Ranzato: The main focus of Dr. Elia Ranzato (ERa) is the development of new and more effective treatment modalities for mesothelioma. ERa's also been focusing on wound repair and regen- eration process. ERa has developed an in vitro human wound-healing model that allows him to investigate the effects of various agents and experimental conditions on the wound re-epithelialization process. ERa is currently using both platelet derivatives and natural compounds (such as lichen extracts and honeys), as experimental tools in order to perform a more in-depth analysis, in terms of cell biology and proteomics, of the mechanisms of wound healing.

Valeria Chiono has a Master Degree in Chemical Engineering summa cum laude, from the University of Pisa (2001) and a Ph.D in Chemical and Materials Engineering from the University of Pisa (2006). Since 2015, she is Associate Professor at the Department of Mechanical and Aerospace Engineering of Politecnico di Torino. Her research activity aims at the development of biomimetic scaffolds with tissue-specific features, based on combinations of synthetic and natural polymers. She is co-author of 60 papers in international journals, 4 book chapters, 4 patents and more than 90 conference proceedings (Scopus H-Index: 19).

Irene Carmagnola was born in 1984 in Torino. She received MS degree (2009) and Ph.D. (2013) in Biomedical Engineering from Politecnico di Torino. From October 2009 to March 2010 she had a grant at the Department of Mechanical and Aerospace Engineering of Politecnico di Torino and from 2013 she is post-doc researcher at the Department of Mechanical and Aerospace Engineering of Politecnico di Torino. Her research activities are focused on the development of biomimetic scaffolds and innovative nanocoatings for biomedical applications. She is co-author of 10 papers in international journals, 2 chapter books and about 30 conference proceedings.

Dr. Masuhiro Tsukada is specially nominated professor, Graduate School of Science and Technology, Shinshu University, Ueda, Japan. Before Shinshu University, he had been working on new biomaterials of silk proteins for 35 years at National Institute of Agrobiological Science, Tsukuba, Ibaraki. Dr. Masuhiro Tsukada has been conducting research for more than 40 years on naturally occurring proteins, such as silks and wool keratin. The major focus of his researches are the chemical modification and grafting towards protein fibres and development new biotechnological applications, biodegradable silk, binding metal cations to modified protein fibres, antimicrobial active silk materials and silk protein nanofibres. 